\title{
Polydeoxyribonucleotide Exerts Therapeutic Effect by Increasing VEGF and Inhibiting Inflammatory Cytokines in Ischemic Colitis Rats
}

\author{
Sung-Eun Kim, ${ }^{1}$ Il-Gyu Ko, ${ }^{1}$ Jun-Jang Jin, ${ }^{1}$ Lakkyong Hwang, ${ }^{1}$ Chang-Ju Kim, ${ }^{1}$ \\ Sang-Hoon Kim, ${ }^{1}$ Jin-Hee Han $\left(\mathbb{D},{ }^{2}\right.$ and Jung Won Jeon $\mathbb{( D}^{3}$ \\ ${ }^{1}$ Department of Physiology, College of Medicine, Kyung Hee University, Seoul, Republic of Korea \\ ${ }^{2}$ Department of Anesthesiology and Pain Medicine, Kyung Hee Medical Center, College of Medicine, Kyung Hee University, \\ Seoul, Republic of Korea \\ ${ }^{3}$ Department of Internal Medicine, Kyung Hee University Hospital at Gangdong, College of Medicine, Kyung Hee University, \\ Seoul, Republic of Korea \\ Correspondence should be addressed to Jung Won Jeon; drglory@naver.com
}

Received 5 September 2019; Revised 14 January 2020; Accepted 24 January 2020; Published 22 February 2020

Academic Editor: Anna Chiarini

Copyright $\odot 2020$ Sung-Eun Kim et al. This is an open access article distributed under the Creative Commons Attribution License, which permits unrestricted use, distribution, and reproduction in any medium, provided the original work is properly cited.

\begin{abstract}
Ischemic colitis is resulted from an inadequate blood supply to a segment or entire colon. Polydeoxyribonucleotide (PDRN), extracted from salmon sperm, has been reported to exert anti-inflammatory and anti-ischemic effects through the adenosine $\mathrm{A}_{2 \mathrm{~A}}$ receptor $\left(A_{2 A} R\right)$. We investigated whether PDRN possesses therapeutic effectiveness on ischemic colitis rats. Ischemic colitis was induced by selective devascularization. The skin temperature on the ischemic colitis-induced region was determined. To assess the colonic damage score and collagen deposition, colonic tissue sections were stained with hematoxylin and eosin (H\&E), and Masson trichrome staining was performed. Western blot analysis for $A_{2 A} R$, vascular endothelial growth factor (VEGF), cyclooxygenase-2 (COX-2), tumor necrosis factor- $\alpha$ (TNF- $\alpha$ ), interleukin- $1 \beta$ (IL-1 $\beta$ ), and IL-6, Bax, Bcl-2, and extracellular signal-regulated kinase $1 / 2$ (ERK1/2) was performed. Skin temperature was increased and mucosal damage and collagen deposition were observed in the affected colonic tissues in the ischemic colitis rats. Expressions of inflammatory cytokines (TNF- $\alpha$, IL-1 $\beta$, and IL-6) and inflammatory mediator (COX-2) were upregulated in the ischemic colitis rats. Apoptosis was increased by decreasing the ratio of Bcl-2 to Bax and by suppressing the phosphorylated form of ERK1/2 expression in the ischemic colitis rats. Treatment with PDRN alleviated mucosal damage reduced the expressions of inflammatory cytokines and COX-2 and inhibited apoptosis in the ischemic colitis rats. PDRN treatment more enhanced the expressions of $A_{2 A} R$ and VEGF in the ischemic colitis rats. PDRN showed therapeutic effectiveness on ischemic colitis by increasing VEGF expression and inhibiting inflammatory cytokines and COX-2 through enhancing $\mathrm{A}_{2 \mathrm{~A}} \mathrm{R}$ expression.
\end{abstract}

\section{Introduction}

Ischemic colitis, the most common ischemic pathology of the gastrointestinal tract, generally results from an inadequate blood supply to a segment of the colon or the entire colon and leading to colonic inflammation and necrosis [1]. Although the incidence of ischemic colitis in the general population is likely underestimated because many cases are misdiagnosed as inflammatory bowel disease, the annual incidence is estimated at 4.5 to 44 cases per 100,000 persons $[2,3]$. Ischemic colitis frequently occurs with old people and female predominance, but it is not necessarily limited to older people and is more likely to develop ischemic colitis in young people with smoking and hyperuricemia [4].

The clinical treatment for ischemic colitis varies widely depending on the cause and degree of ischemia. Although there are various etiologies of ischemic colitis, which are unidentified in most cases, the important underlying 
mechanism is ischemia [1]. The colon is susceptible to ischemia due to its anatomical and physiological features, including relatively low blood flow and less-developed microvasculature plexus compared to the rest of the gastrointestinal system [5]. Moreover, in cases of hypotension, compensatory homeostatic mechanisms redirect blood flow to the brain at the expense of the visceral circulation [6]. Although ischemia is regarded as a self-limiting process of acute inflammation, the gut, as the origin and/or target of numerous inflammatory cytokines, plays an important role in local injury, and it is involved in systemic inflammation related to multiple-organ dysfunction or failure [7]. Likewise, during the onset of ischemic colitis, various factors promote inflammation of colonic endothelial cells, which increase tissue damage [8]. In particular, colonic and intestinal endothelial cell environment possesses both isoforms of cyclooxygenase (COX), and their induction has been demonstrated to occur in response to different inflammatory cytokines, such as interleukin- $1 \alpha$ (IL- $1 \alpha)$, IL- $1 \beta$, and tumor necrosis factor- $\alpha$ (TNF- $\alpha$ ). COX2 is induced by inflammatory stimuli and synthesizes prostaglandins, which mediate the inflammatory process and tissue damage $[9,10]$.

Angiogenesis is a pivotal process in all types of wound healing, including gastric and colonic mucosal healing $[11,12]$. It is regulated by many proangiogenic factors, such as vascular endothelial growth factor (VEGF), fibroblast growth factor, and endothelial growth factor. Of the many growth factors, VEGF is the most potent stimulus for angiogenesis and it plays an important role in colonic mucosal healing [11].

Apoptosis is controlled by the intrinsic pathway or extrinsic pathway or both. The extrinsic pathway is activated by ligand-induced cell surface receptors, such as tumor necrosis factor receptor (TNFR) and Fas. The intrinsic mitochondrial apoptosis pathway is induced by activation of apoptosis-related proteins, including $\mathrm{Bax}$ and $\mathrm{Bcl}-2$, or other signaling pathways, including the mitogen-activated protein kinase (MAPK), phospholipase $\mathrm{C} \gamma$-1 (PLC- $\gamma 1$ ), and phosphatidylinositol 3-kinase (PI3K)/protein kinase B (Akt) pathways [13]. Extracellular signal-regulated kinase 1/2 (ERK1/2) is one of the MAPK families and modulates cell growth, differentiation, and survival $[14,15]$. Apoptosis in intestinal epithelial cells is implicated in the occurrence and procession of inflammatory bowel diseases [16].

Polydeoxyribonucleotide (PDRN) is a mixture of nucleotides with molecular weights of $50-1500 \mathrm{kDa}$ that originates from the human placenta or salmon sperm [17]. PDRN facilitates skin regeneration by activating adenosine $A_{2 A}$ receptor $\left(A_{2 A} R\right)$ [17]. $A_{2 A} R$ is involved in the anti-inflammatory pathway and in the VEGF production $[17,18]$. PDRN inhibits apoptosis and exerts anti-inflammatory effect by suppressing the production of inflammatory cytokines $[12,18]$.

Thus, enhancing VEGF production and suppressing inflammation are the therapeutic strategies for the treatment of ischemic colitis. In the present study, we investigated whether PDRN possesses therapeutic effectiveness on ischemic colitis rats.

\section{Materials and Methods}

2.1. Experimental Animals. Seven-week-old male Sprague Dawley rats weighing $180 \pm 5 \mathrm{~g}(n=50)$ were used in this study. All experimental procedures were performed in accordance with the Guidelines for the Care and Use of Animals of the National Institutes of Health (NIH). This study was approved by the Institutional Animal Care and Use Committee of Kyung Hee University (KHUASP[SE]14-038). Experimental animals were randomly divided into 5 groups ( $n=10$ in each group): sham-operated group, ischemic colitis-induced group, ischemic colitis-induced and $4 \mathrm{mg} / \mathrm{kg}$ PDRN-treated group, ischemic colitis-induced and $8 \mathrm{mg} / \mathrm{kg}$ PDRN-treated group, and ischemic colitis-induced and $16 \mathrm{mg} / \mathrm{kg}$ PDRN-treated group. Animals were provided food and water ad libitum and maintained at $24 \pm 2^{\circ} \mathrm{C}$ with $60 \%$ humidity under a $12 \mathrm{~h}$ light/dark photoperiod (lights on at 7:00 a.m.).

\subsection{Induction of Ischemic Colitis and Treatments.} Ischemic colitis was induced by selective devascularization, using a modified technique described by Irkorucu et al. [19]. The rats were anesthetized with Zoletil $50^{\circledR}(10 \mathrm{mg} / \mathrm{kg}$, i.p.; Virbac Laboratories, Carros, France) and laparotomized. Subsequently, the rats underwent selective devascularization of a $4 \mathrm{~cm}$ segment of the descending colon by marginal vessel ligation at 4 points, with all of the vasa recta in between. The midline incision was sutured, and the rats were returned to their cages with free access to food and water for recovery following surgery. A sham laparotomy was performed on rats in the sham-operated group.

The rats were treated with PDRN (Rejuvenex ${ }^{\mathrm{TM}}$; Pharma Research Products, Seongnam, Korea) $48 \mathrm{~h}$ after induction of ischemic colitis. The timing of PDRN treatment in this study was performed considering the clinical and pathological progress of ischemic colitis $[6,20]$. PDRN diluted in $0.9 \%$ saline $(500 \mu \mathrm{L})$ was injected intraperitoneally at respective dose $(4,8$, and $16 \mathrm{mg} / \mathrm{kg}$ of body weight) daily for 21 consecutive days. To confirm the involvement of adenosine $\mathrm{A}_{2 \mathrm{~A}}$ receptor in $\mathrm{PDRN}, 16 \mathrm{mg} / \mathrm{kg}$ 3,7-dimethyl-1-propargylxanthine (DMPX; Sigma Chemical Co., St. Louis, MO, USA) was applied. The rats in the sham-operated group and in the ischemic colitis-induced group received an equivalent volume of $0.9 \%$ saline intraperitoneally for the same duration.

\subsection{Measurement of Skin Temperature on the Ischemic Colitis-} Induced Region. The skin temperature on the ischemic colitis-induced region was determined weekly using an infrared digital thermometer (MT6; Raytek Co., Santa Cruz, CA, USA).

\subsection{Macroscopic Analysis and Tissue Preparation.} Immediately before sacrifice, the rats were anesthetized with an intraperitoneal injection of Zoletil $50^{\circledR}(10 \mathrm{mg} / \mathrm{kg})$, and the laparotomy was reperformed. For macroscopic evaluation, the devascularized segment of the colon was exposed 
and photographed at the same angle and distance. Morphological damage score was evaluated with the Wallace macroscopic score (Table 1) [21].

Immediately after photographing, the rats were sacrificed, and the colon was excised. Excised colonic tissues were immediately frozen at $-80^{\circ} \mathrm{C}$ for western blot analysis and were fixed with a freshly prepared solution of $4 \%$ paraformaldehyde in $100 \mathrm{mM}$ phosphate buffer (pH 7.4) for $24 \mathrm{~h}$ for histological staining. Following dehydration with 70,80 , 90, and $100 \%$ ethanol, the colonic tissue samples were embedded in paraffin and sectioned ( $5 \mu \mathrm{m}$ thickness) using a paraffin microtome (Shandon Finesse 325; Thermo Electron Corp., Somerset, NJ, USA). The paraffin-embedded colonic tissue sections were mounted onto gelatin-coated slides and dried in an oven at $37^{\circ} \mathrm{C}$ overnight.

2.5. Hematoxylin and Eosin (H↔E) Staining. For morphologic examination, the colonic tissue sections were stained with hematoxylin and eosin (H\&E) and evaluated under a light microscope (Olympus, Tokyo, Japan), according to the previously described method $[15,16]$. The sections were stained with Mayer's hematoxylin (Sigma-Aldrich, St. Louis, MO, USA) for $30 \mathrm{sec}$, washed, and stained with eosin (Sigma-Aldrich) for an additional $3 \mathrm{sec}$. Following dehydration, the slides were mounted using Permount ${ }^{\circledR}$ (Fisher Scientific, Fair Lawn, NJ, USA). Ischemic colonic damage was evaluated with the Wallace microscopic score (Table 1) [21].

2.6. Masson Trichrome Staining. To detect collagen fibers in colonic tissues, Masson trichrome staining was performed, according to the previously described method [22]. The sections were deparaffinized and rehydrated with xylene and 100, 95, and 70\% ethanol. After washing, the sections were fixed with Bouin's solution (SigmaAldrich) for $1 \mathrm{~h}$ at $56^{\circ} \mathrm{C}$ and stained with Weigert's iron hematoxylin (Sigma-Aldrich) for $10 \mathrm{~min}$. After rinsing with running tap water, the sections were stained with Biebrich scarlet-acid fuchsin (Sigma-Aldrich) and then differentiated by incubation in phosphomolybdic-phosphotungstic acid solution (Sigma-Aldrich) for 10-15 min. Without rinsing, the sections were stained with aniline blue solution (Sigma-Aldrich) for $5 \mathrm{~min}$ and a light green solution for $1 \mathrm{~min}$, successively. After rinsing, the sections were differentiated in glacial acetic solution for $5 \mathrm{~min}$, dehydrated quickly with $95 \%$ ethanol, and cleared with xylene. The slides were mounted with Permount ${ }^{\circledR}$ (Fisher Scientific). After Masson's trichrome staining, the collagen fibers, nuclei, and background were stained blue, black, and red, respectively.

The fibrosis analysis was conducted according to the previously described method [23]. The collagen/area ratio was analyzed also for 3 areas on each slide by Image-Pro ${ }^{\circledR}$ plus computer-assisted image analysis system (Media Cybernetics Inc., Silver Spring, MD, USA) attached to a light microscope (Olympus), and a mean ratio was defined by three investigators separately.
TABle 1: Wallace macroscopic and microscopic colonic damage score.

\begin{tabular}{cc}
\hline Score & Appearance \\
\hline $\begin{array}{cc}\text { Macroscopic } \\
0\end{array}$ & Normal \\
1 & Local hyperemia without ulceration \\
2 & Ulceration without hyperemia \\
3 & Ulceration with hyperemia at one site \\
4 & Ulceration with hyperemia at two of more sites \\
5 & Ulceration extending more than $2 \mathrm{~cm}$ at several \\
Microscopic & sites \\
0 & Normal \\
1 & Focal ulceration limited to mucosa \\
2 & Focal, transmural inflammation and ulceration \\
3 & Extensive transmural ulceration and inflammation \\
4 & bordered by normal mucosa \\
5 & Extensive transmural ulceration and inflammation \\
& involving entire section \\
\hline
\end{tabular}

2.7. Western Blot Analysis. According to the previously described method $[12,24]$, western blot analysis was performed. The colonic tissues were lysed in a lysis buffer consisting of $50 \mathrm{mM}$ HEPES (pH 7.5), $150 \mathrm{mM} \mathrm{NaCl}, 10 \%$ glycerol, 1\% Triton X-100, $1 \mathrm{mM}$ PMSF, $1 \mathrm{mM}$ EGTA, $1.5 \mathrm{mM} \mathrm{MgCl} 2 \cdot 6 \mathrm{H}_{2} \mathrm{O}, 1 \mathrm{mM}$ sodium orthovanadate, and $100 \mathrm{mM}$ sodium fluoride. The tissue lysate was incubated for $20 \mathrm{~min}$ at $4^{\circ} \mathrm{C}$ and then centrifuged at $14,000 \mathrm{rpm}$ for $30 \mathrm{~min}$.

Protein content was determined using the Bio-Rad colorimetric protein assay kit (Bio-Rad, Hercules, CA, USA). Protein $(20 \mu \mathrm{g})$ was separated on SDS-polyacrylamide gels and transferred onto nitrocellulose membranes, which were incubated with the following antibodies: rabbit anti-GAPDH (1:5,000; AbFrontier, Seoul, Korea), rabbit anti- $\mathrm{A}_{2 \mathrm{~A}} \mathrm{R}$ (1: 1000; Abcam, Cambridge, MA, USA), mouse anti-Bcl-2 (1 : 1,000; Santa Cruz Biotechnology, Santa Cruz, CA, USA), mouse anti-Bax (1 :1,000; Santa Cruz Biotechnology), mouse anti-caspase-3 (1:1,000; Santa Cruz Biotechnology), goat anti-COX-2 ( $1: 1,000$; Santa Cruz Biotechnology), goat antiTNF- $\alpha$ ( $1: 1,000$; Santa Cruz Biotechnology), goat anti-IL-6 $(1: 1,000$; Santa Cruz Biotechnology), rabbit anti-IL-1 $\beta$ (1: 1,000; Santa Cruz Biotechnology), mouse anti-VEGF (1: 1,000; Santa Cruz Biotechnology), rabbit anti-total p44/42 MAPK (ERK1/2) $(1: 1,000$, Cell Signaling Technology Inc., Beverly, Massachusetts, USA), and rabbit anti-phospho-p44/ 42 MAPK (p-ERK1/2) $(1: 1,000$, Cell Signaling Technology Inc.). As secondary antibodies, a horseradish peroxidaseconjugated anti-rabbit antibody $(1: 5,000$; Vector Laboratories Inc., Burlingame, CA, USA) was used for GAPDH, $\mathrm{A}_{2 \mathrm{~A}} \mathrm{R}, \mathrm{IL}-1 \beta, \mathrm{ERK} 1 / 2$, and p-ERK1/2. A horseradish peroxidase-conjugated anti-mouse antibody $(1: 5,000$; Amersham Pharmacia Biotech GmbH, Freiburg, Germany) was used for Bcl-2, Bax, caspase-3, and VEGF. A horseradish peroxidase-conjugated anti-goat antibody $(1: 10,000$; Vector Laboratories Inc.) was used for COX-2, TNF- $\alpha$, and IL-6.

All of the experimental procedures for western blot were performed under standard laboratory conditions and at room temperature, except for the membrane transfer, which 
was performed at $4^{\circ} \mathrm{C}$ with a cold pack and prechilled buffer. Bands from the western blot were detected using the enhanced chemiluminescence (ECL) detection kit (Bio-Rad). To compare the relative expression levels of the proteins, the density of the detected bands was measured using Molecular Analyst $^{\mathrm{TM}}$, version 1.4.1 (Bio-Rad).

2.8. Data Analysis. The data were analyzed with one-way ANOVA and Duncan's post hoc test. All values are expressed as the mean \pm standard error of the mean (SEM). $P$ value less than 0.05 was considered significant.

\section{Results}

3.1. Skin Temperature. Skin temperature on the ischemic colitis-induced region is presented in Figure 1. Induction of ischemic colitis significantly increased the skin temperature of the lesion compared to that in sham rats, and the increased skin temperature was maintained for the first week of treatment with PDRN $(P<0.05)$. However, after 2 weeks, PDRN treatment significantly and dose-dependently decreased the skin temperature of the lesion, and the high dose of PDRN $(16 \mathrm{mg} / \mathrm{kg})$ most effectively reduced skin temperature $(P<0.05)$.

3.2. Morphological and Histological Changes. The appearance of the devascularized colon at 3 weeks after induction of ischemic colitis is shown in Figure 2 (left column). Hyperemia and edema were observed in the ischemic colitisinduced rats. PDRN treatment for 3 weeks ameliorated these morphological changes. Colonic mucosa in the sham-operated rats showed a normal appearance with intact epithelium. In contrast, mucosa in the ischemic colitis-induced rats showed mucosal damage with losses of goblet cells and abnormal crypts. PDRN treatment remarkably alleviated the mucosal damage induced by selective devascularization of the colon (Figure 2, middle column). Collagen deposition in the colonic tissue was increased, especially in the mucosal layer, by induction of ischemic colitis. PDRN treatment reduced collagen deposition in the colonic tissue (Figure 2, right column).

These changes led to elevated colonic damage score and collagen $(P<0.05)$. However, PDRN treatment resulted in the dose-dependent decrease in colonic damage score and collagen $(P<0.05)$.

3.3. $A_{2 A} R$ and VEGF Expressions. Induction of ischemic colitis increased $\mathrm{A}_{2 \mathrm{~A}} \mathrm{R}(45 \mathrm{kDa})$ and VEGF $(21 \mathrm{kDa})$ expressions in the colonic tissue $(P<0.05)$. Treatment with PDRN further enhanced $\mathrm{A}_{2 \mathrm{~A}} \mathrm{R}$ and VEGF expressions $(P<0.05)$ (Figure 3).

3.4. COX-2, TNF- $\alpha, \quad I L-1 \beta$, and IL-6 Expressions. Induction of ischemic colitis increased the expressions of inflammatory proteins, such as COX-2 (70-72 kDa), TNF- $\alpha$ $(17 \mathrm{kDa})$, IL-1 $\beta(17 \mathrm{kDa})$, and IL-6 $(22-27 \mathrm{kDa})$ in the colonic tissue $(P<0.05)$. In contrast, PDRN treatment dose-

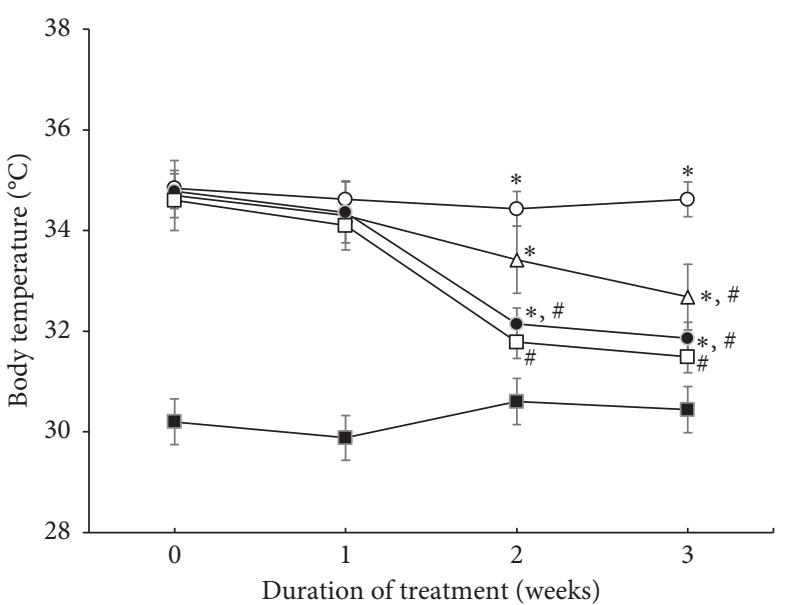

FIGURE 1: Changes in the skin temperature in ischemic colitisinduced region. ( $\square)$ The sham-operated group, $(O)$ the ischemic colitis-induced group, $(\triangle)$ the ischemic colitis-induced and $4 \mathrm{mg} /$ kg PDRN-treated group, $(\bullet)$ the ischemic colitis-induced and $8 \mathrm{mg} / \mathrm{kg}$ PDRN-treated group, and $(\square)$ the ischemic colitis-induced and $16 \mathrm{mg} / \mathrm{kg}$ PDRN-treated group. ${ }^{*} P<0.05$ versus sham-operated group, ${ }^{\#} P<0.05$ versus ischemic colitis-induced group.

dependently reduced COX-2, TNF- $\alpha$, IL- $1 \beta$, and IL-6 expressions in the colonic tissue $(P<0.05)$ (Figure 4$)$.

3.5. Bcl-2, Bax, Caspase-3, and Phospho-p44/42 MAPK ( $p$ ERK1/2) Expressions. Induction of ischemic colitis increased Bax $(24 \mathrm{kDa})$ and $\mathrm{Bcl}-2(26-29 \mathrm{kDa})$ expressions in the colonic tissues. However, the increase of Bax expression was greater than $\mathrm{Bcl}-2$ expression, and consequently, Bcl-2 to Bax ratio was lower in the ischemic colitis-induced rats than in the normal rats $(P<0.05)$. In contrast, treatment with PDRN increased the expression of $\mathrm{Bcl}-2$; as a result, $\mathrm{Bcl}-2$ to Bax ratio was higher in the $16 \mathrm{mg} / \mathrm{kg}$ PDRN treatment $(P<0.05)$ (Figure 5, left). Induction of ischemic colitis led to an increase in the caspase-3 $(32 \mathrm{kDa})$ expression $(P<0.05)$. However, PDRN treatment dose-dependently inhibited caspase-3 expression $(P<0.05)$ (Figure 5, right-upper).

Induction of ischemic colitis decreased the expression of phospho-p44/42 MAPK (p-ERK1/2, 42 and $44 \mathrm{kDa}$ ) in the colonic tissue when compared to the levels in normal rats $(P<0.05)$. Conversely, PDRN treatment dose-dependently increased the expression of p-ERK1/2 $(P<0.05)$ (Figure 5, right-lower).

3.6. Evaluation of Efficacy in PDRN through DMPX. Induction of ischemic colitis increased TNF- $\alpha$, IL- $1 \beta$, and IL-6 expressions, whereas decreased adenosine $\mathrm{A}_{2 \mathrm{~A}}$ receptor expression $(P<0.05)$ (Figure 6). PDRN treatment suppressed expression of TNF- $\alpha$, IL- $1 \beta$, and IL- 6 , in contrast enhanced the adenosine $\mathrm{A}_{2 \mathrm{~A}}$ receptor expression $(P<0.05)$ (Figure 6). In the case of PDRN + DMPX treatment, TNF- $\alpha$, IL- $1 \beta$, and IL- 6 levels were not changed compared to ischemic colitis-induced group. Likewise, PDRN + DMPX treatment showed no change in adenosine $\mathrm{A}_{2 \mathrm{~A}}$ receptor expression compared to ischemic colitis group. 

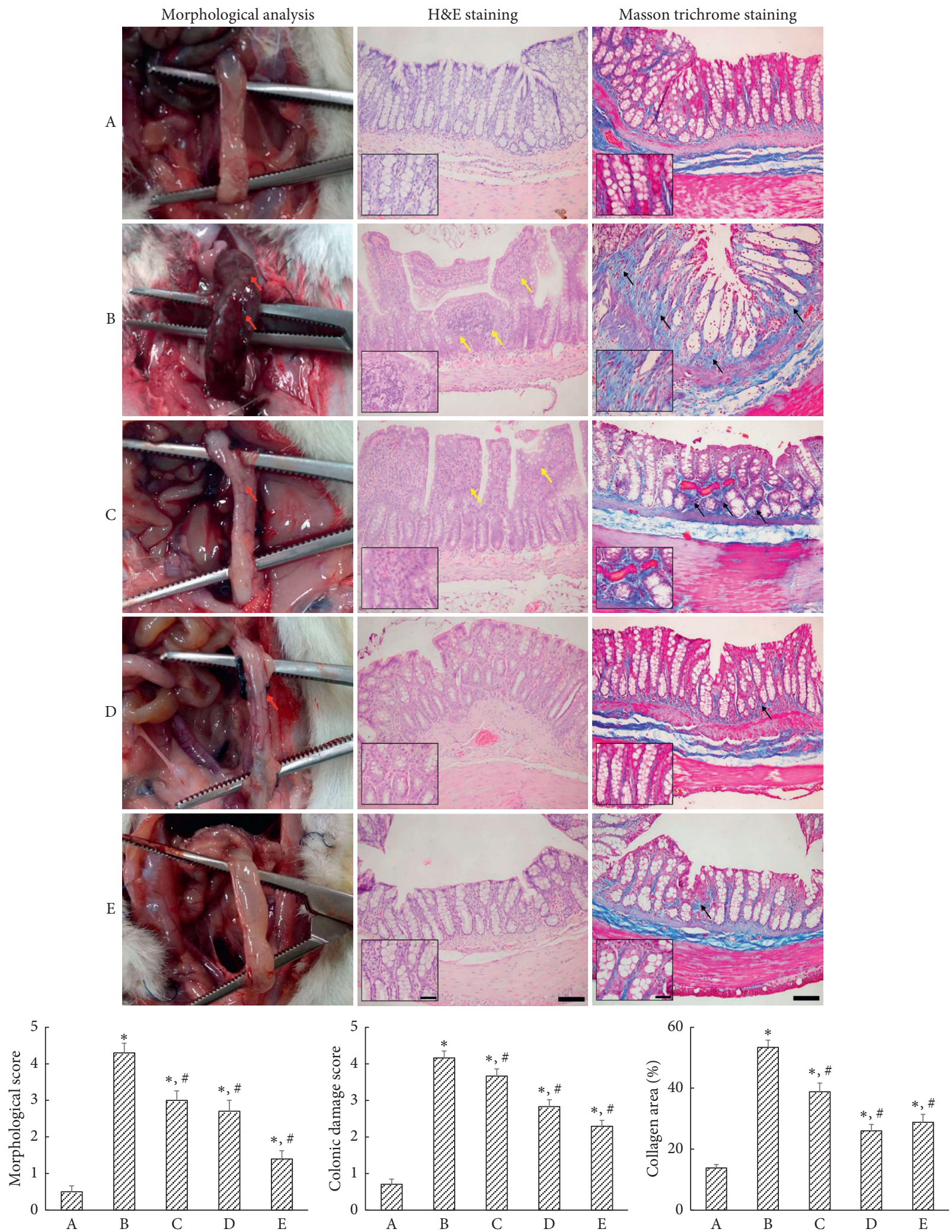

Figure 2: Ischemic colitis-induced morphological and histological changes. Left column: morphological analysis. Red arrows indicate hyperemia and ulceration. Middle column: hematoxylin and eosin staining (nuclei were stained blue and fibers were stained pink). Yellow arrows indicate loss of epithelial cells and distortion of mucosa. Right column: Masson trichrome staining (cytoplasm was stained pink and collagen fibers were stained blue). Black arrows indicate collagen deposition. Lower column: morphological score, colonic damage score, and collagen in each group. (A) The sham-operated group, (B) the ischemic colitis-induced group, (C) the ischemic colitis-induced and $4 \mathrm{mg} / \mathrm{kg}$ PDRN-treated group, (D) the ischemic colitis-induced and $8 \mathrm{mg} / \mathrm{kg}$ PDRN-treated group, and (E) the ischemic colitis-induced and $16 \mathrm{mg} / \mathrm{kg}$ PDRN-treated group. Inset shows histological damage and collagen fibers. The scale bar represents $150 \mu \mathrm{m}$ (A-E). Insets are higher magnification (scale bar: $50 \mu \mathrm{m}$ ). ${ }^{*} P<0.05$ versus sham-operated group, ${ }^{\sharp} P<0.05$ versus ischemic colitis-induced group. 

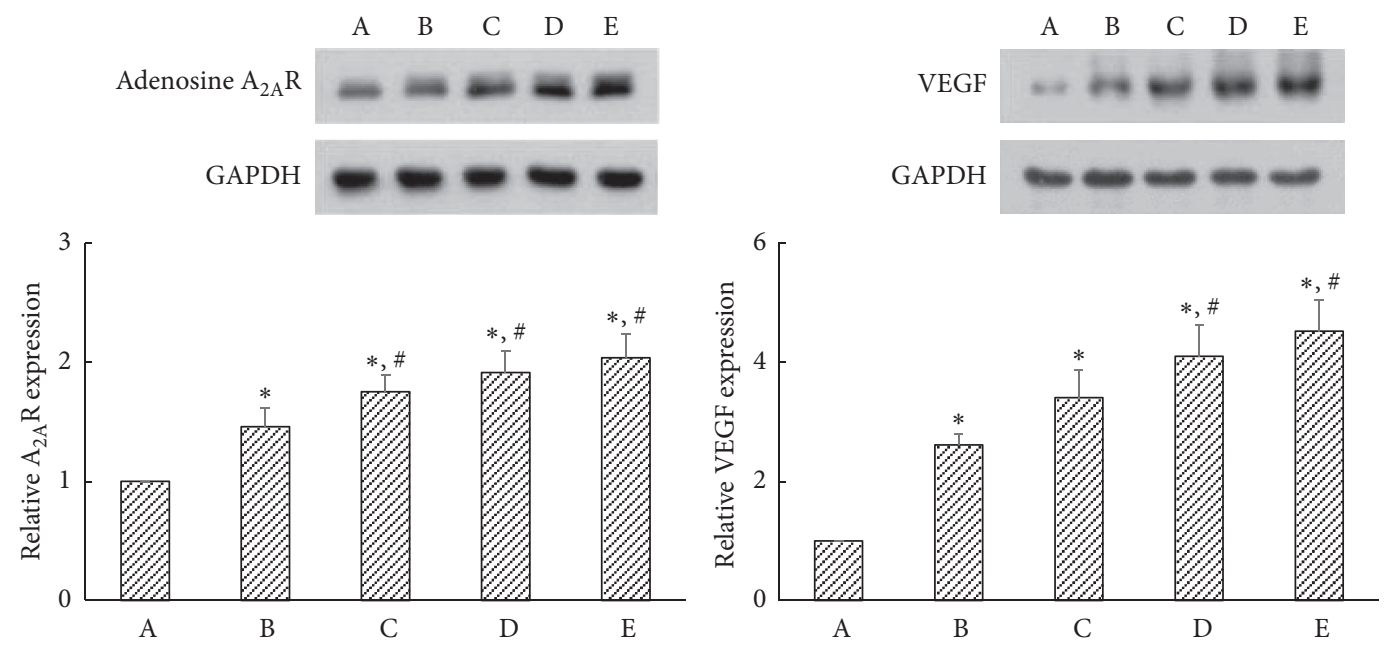

FIGURE 3: Effects of polydeoxyribonucleotide (PDRN) on the expressions of adenosine A2A receptor $\left(\mathrm{A}_{2 \mathrm{~A}} \mathrm{R}\right)$ and vascular endothelial growth factor (VEGF) in ischemic colitis-induced tissues. (A) Sham-operated group, (B) ischemic colitis-induced group, (C) ischemic colitis-induced and $4 \mathrm{mg} / \mathrm{kg}$ PDRN-treated group, (D) ischemic colitis-induced and $8 \mathrm{mg} / \mathrm{kg}$ PDRN-treated group, and (E) ischemic colitisinduced and $16 \mathrm{mg} / \mathrm{kg}$ PDRN-treated group. ${ }^{*} P<0.05$ versus sham-operated group, ${ }^{\#} P<0.05$ versus ischemic colitis-induced group.
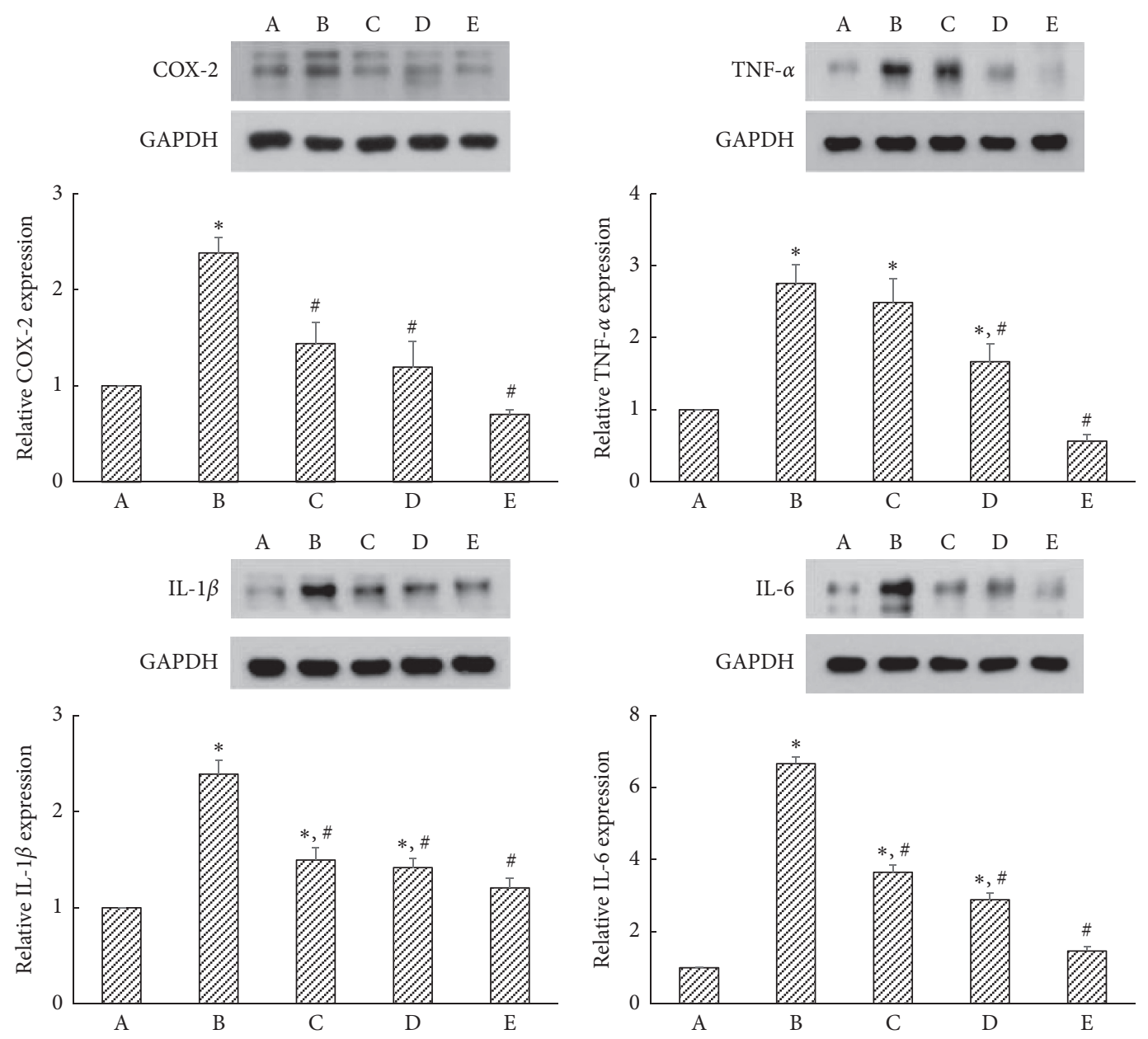

FIGURE 4: Effects of polydeoxyribonucleotide (PDRN) on the expressions of cyclooxygenase-2 (COX-2), tumor necrosis factor- $\alpha$ (TNF- $\alpha$ ), interleukin-1 $\beta$ (IL-1 $\beta$ ), and IL-6 in ischemic colitis-induced tissues. (A) Sham-operated group, (B) ischemic colitis-induced group, (C) ischemic colitis-induced and $4 \mathrm{mg} / \mathrm{kg}$ PDRN-treated group, (D) ischemic colitis-induced and $8 \mathrm{mg} / \mathrm{kg}$ PDRN-treated group, and (E) ischemic colitis-induced and $16 \mathrm{mg} / \mathrm{kg}$ PDRN-treated group. ${ }^{*} P<0.05$ versus sham-operated group, ${ }^{\#} P<0.05$ versus ischemic colitisinduced group. 

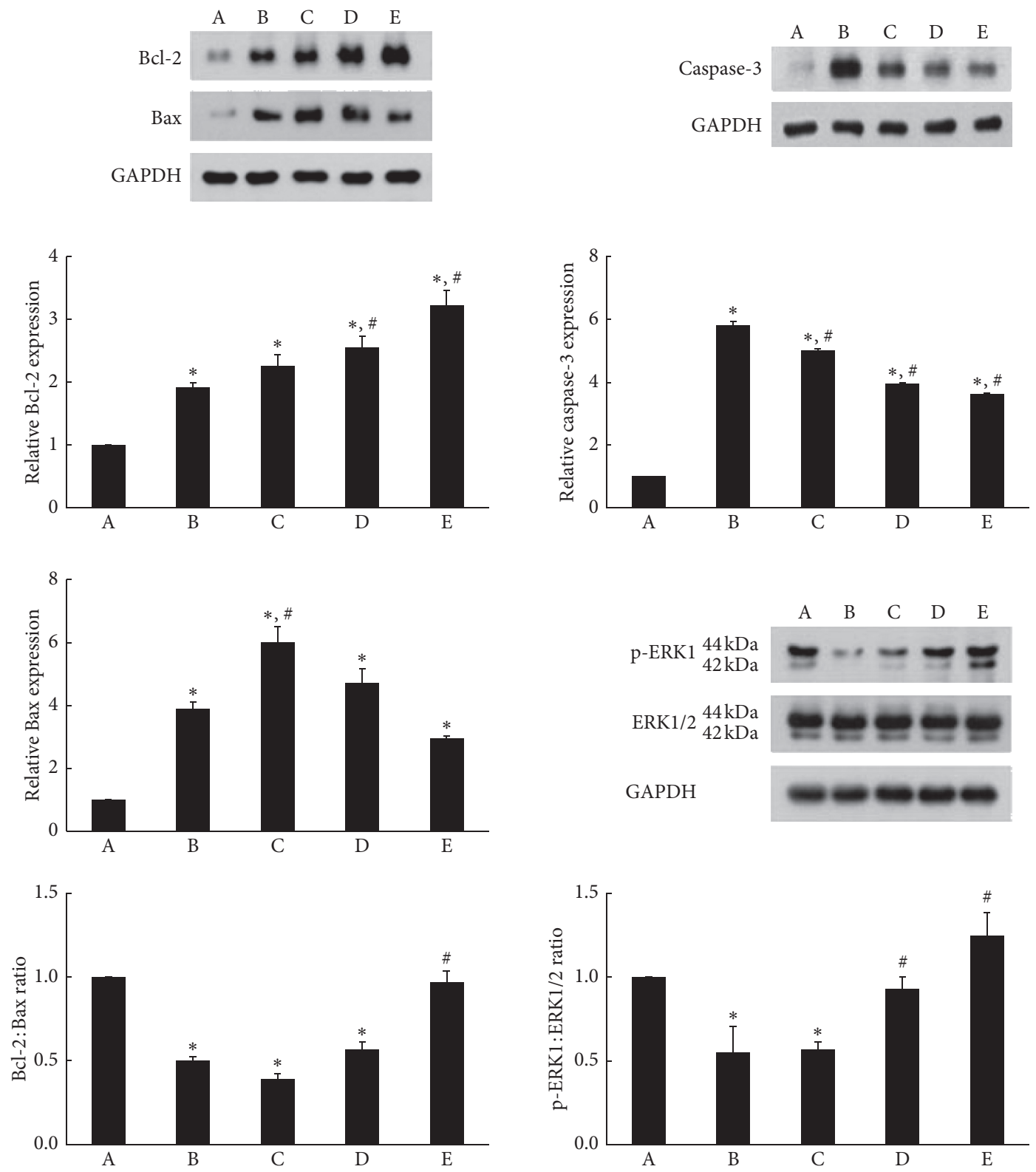

FIGURE 5: Effects of polydeoxyribonucleotide (PDRN) on the expressions of Bcl-2, Bax, caspase-3, and extracellular signal-regulated kinase $1 / 2($ ERK1/2) in ischemic colitis-induced tissues. (A) Sham-operated group, (B) ischemic colitis-induced group, (C) ischemic colitisinduced and $4 \mathrm{mg} / \mathrm{kg}$ PDRN-treated group, (D) ischemic colitis-induced and $8 \mathrm{mg} / \mathrm{kg}$ PDRN-treated group, and (E) ischemic colitisinduced and $16 \mathrm{mg} / \mathrm{kg}$ PDRN-treated group. ${ }^{*} P<0.05$ versus sham-operated group, ${ }^{\#} P<0.05$ versus ischemic colitis-induced group.

\section{Discussion}

Inflammatory cytokines, such as TNF- $\alpha$, IL-1 $\beta$, and IL-6, are frequently upregulated in the animal models of experimental colitis $[25,26]$. Increased level of TNF- $\alpha$ was observed in the serum of patients with ulcerative colitis and Crohn's disease $[27,28]$. IL- 6 induces TNF- $\alpha$ and IL- $1 \beta$ production, and IL- 6 also increases the expression of adhesion proteins, including intercellular adhesion molecule-1 (ICAM-1), involved in the activation and migration of inflammatory cells to the intestine [29]. IL-6 was elevated during intestinal ischemia and further increased during reperfusion [7]. Increased levels of TNF- $\alpha$ and IL- $1 \beta$ in the ischemic intestine caused the progress of intestinal injury [30]. As a result, double inhibition of TNF- $\alpha$ and IL- $1 \beta$ can effectively ameliorate postischemic deterioration of the intestine. PDRN reduced the expressions of inflammatory cytokines and altered the expression of apoptotic markers [26]. Specific COX-2 inhibitors ameliorated the symptoms of inflammation [31]. In the present study, treatment with PDRN effectively suppressed ischemic colitis-induced COX-2, TNF- $\alpha$, IL- $1 \beta$, and IL-6 expressions in the colonic tissues (Figure 4). The present results showed that PDRN potently inhibited inflammation in the ischemic colitis rats.

Adenosine suppresses TNF- $\alpha$ release from macrophages, primarily through $\mathrm{A}_{2 \mathrm{~A}} \mathrm{R}$ [32]. Activation of $\mathrm{A}_{2 \mathrm{~A}} \mathrm{R}$ has a robust anti-inflammatory effect, and $\mathrm{A}_{2 \mathrm{~A}} \mathrm{R}$ is involved in the repair of experimental colitis $[33,34]$. PDRN potentiated 

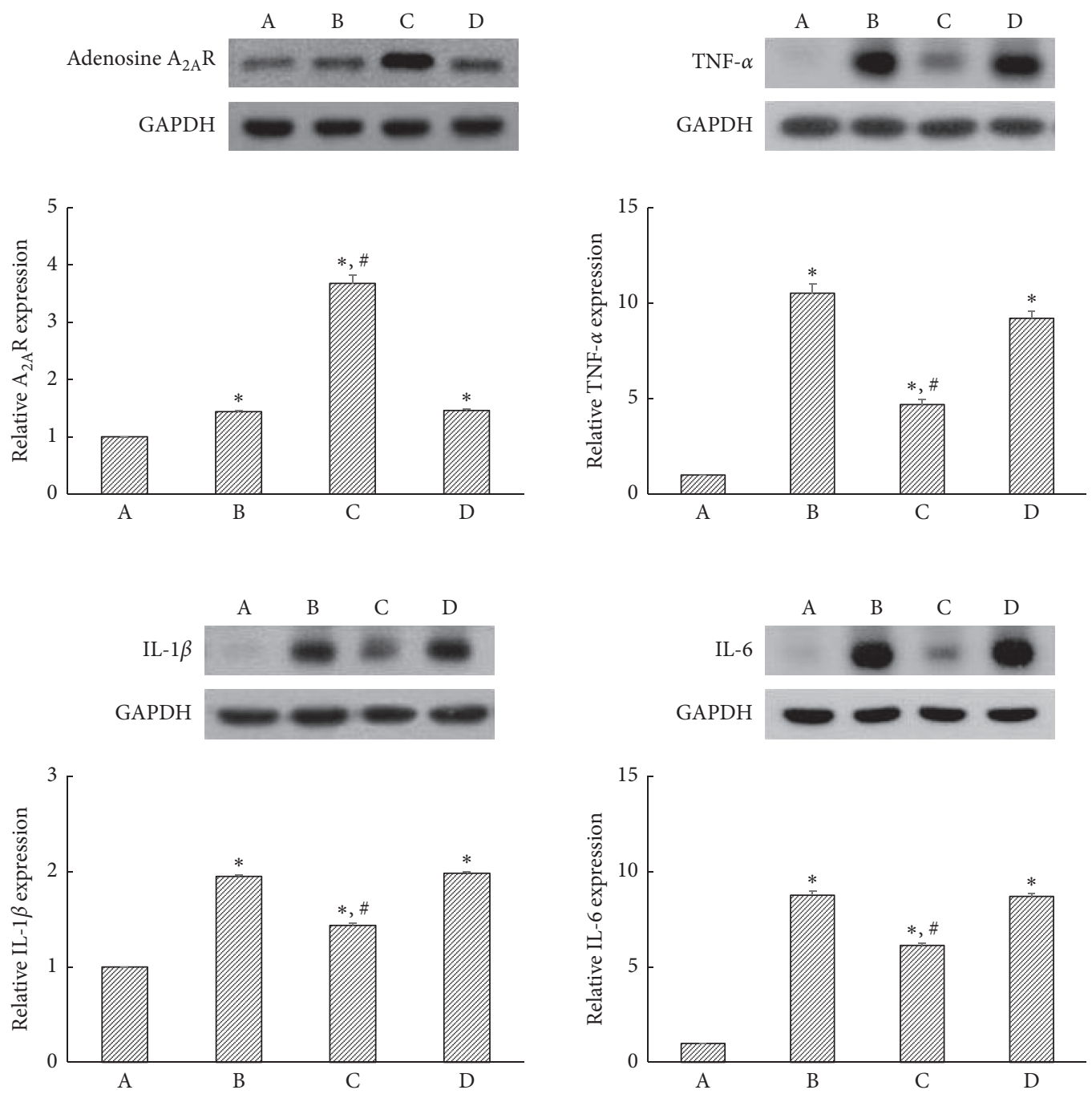

FIGURE 6: Effects of polydeoxyribonucleotide (PDRN) and 3,7-dimethyl-1-propargylxanthine (DMPX) on the expressions of adenosine $\mathrm{A}_{2 \mathrm{~A}}$ receptor $\left(\mathrm{A}_{2 \mathrm{~A}} \mathrm{R}\right)$, tumor necrosis factor- $\alpha$ (TNF- $\alpha$ ), interleukin- $1 \beta$ (IL-1 $\left.\beta\right)$, and IL-6 in ischemic colitis-induced tissues. (A) Sham-operated group, (B) ischemic colitis-induced group, (C) ischemic colitis-induced and $16 \mathrm{mg} / \mathrm{kg}$ PDRN-treated group, and (D) ischemic colitisinduced and $16 \mathrm{mg} / \mathrm{kg}$ PDRN $+16 \mathrm{mg} / \mathrm{kg}$ DMPX-treated group. ${ }^{*} P<0.05$ versus sham-operated group, ${ }^{\#} P<0.05$ versus ischemic colitisinduced group.

gastric healing by activation of $\mathrm{A}_{2 \mathrm{~A}} \mathrm{R}$ in gastric ulcer rats [24]. In the present study, induction of ischemic colitis increased $A_{2 A} R$ expression and PDRN treatment further increased $\mathrm{A}_{2 \mathrm{~A}} \mathrm{R}$ expression in colonic tissue (Figure 3, left). The present results showed that the effects of PDRN appeared through the enhancing of $\mathrm{A}_{2 \mathrm{~A}} \mathrm{R}$ expression.

Fibrosis is considered as a consequence of chronic inflammation in inflammatory bowel disease [35]. Theiss et al. [36] suggested that TNF- $\alpha$ is associated with intestinal fibrosis, since TNF- $\alpha$ induces collagen accumulation and proliferation in intestinal myofibroblasts. Clinically, ischemic colitis is classified as full-thickness transmural colitis and partial-thickness ischemic colitis. The first type is associated with gangrene and multiorgan failure, while the latter is confined to the mucosa and submucosa [1]. In the present study, mucosal damage induced by selective devascularization was observed, which was effectively prevented by PDRN treatment. Administration of PDRN decreased collagen deposition in colonic tissue (Figure 2). The present results showed that PDRN alleviated mucosal damage and decreased collagen deposition in the ischemic colitis rats.

In addition, body temperature is a marker of severity in colitis and inflammation [37], and an increase in skin temperature is an indicator of inflammation. Pallio et al. [26] reported that PDRN improved the features and clinical symptoms of colitis, such as fever, weight loss, and histological alterations. In the present study, PDRN treatment reduced the colitis-induced increase of skin temperature (Figure 1). The present results showed that PDRN relieved the symptoms of ischemic colitis.

Two ischemic factors, VEGF and hypoxia-inducible factor- $1 \alpha$ (HIF- $1 \alpha$ ), were constitutively expressed in the human colon tissue and overexpressed in the ischemic colitis lesion [38]. In ischemic crises, VEGF and HIF- $1 \alpha$ were immediately induced and participated in the prevention 
against the expansion of tissue damage as well as for the repairing damaged tissue [38]. Under ischemic conditions, activation of $\mathrm{A}_{2 \mathrm{~A}} \mathrm{R}$ stimulated VEGF production in macrophages [39]. PDRN facilitated blood flow via stimulation of VEGF in an experimental model of ischemic skin flaps. Increased level of VEGF contributed to angiogenesis and symptom improvement $[40,41]$. PDRN maintained high VEGF level during angiogenesis and restoration of blood flow through activation of $\mathrm{A}_{2 \mathrm{~A}} \mathrm{R}$ [18]. Thus, PDRN can be considered to possess anti-ischemic effect [33]. Our study also showed that induction of ischemic colitis increased VEGF expression and PDRN treatment further increased VEGF expression in colonic tissue (Figure 3, right). The present results showed that PDRN facilitated vascularization in the ischemic colitis rats.

Apoptosis was increased in ischemic colitis rats along with inflammation and oxidative damage [8]. Excessive apoptosis damages mucosal integrity and barrier function, leading to mucous epithelial injury, ulcerative formation, inflammatory cell infiltration, and other conditions related to colitis [13, 42]. Pallio et al. [26] reported that PDRN treatment affected Bax and Bcl-2 expressions in experimental colitis by reducing the numbers of apoptotic and necrotic cells in all tissue layers. In their study, TNF- $\alpha$ induced either apoptosis or necrosis depending on cell types, environmental conditions, and the magnitude of the cellular insults [26]. Increase of Bcl-2 to Bax ratio represents suppression of apoptosis [43, 44]. In addition, caspase- 3 , which is the most widely studied caspase, is a key executor of apoptosis [45].

In the present study, induction of ischemic colitis affected the expressions of Bcl-2 and Bax, resulting in decrement of the ratio of antiapoptotic protein $\mathrm{Bcl}-2$ to proapoptotic protein Bax. However, PDRN treatment increased Bcl-2 and suppressed Bax, resulting in enhancement of the ratio of Bcl-2 to Bax (Figure 5, left). Furthermore, our present study showed that PDRN treatment suppressed the ischemic colitis-induced increase in caspase- 3 expression (Figure 5, right-upper). The present results showed that PDRN suppressed apoptosis in the ischemic colitis rats.

The protective effect of ERK activation is mediated by antiapoptotic members of the Bcl-2 family, including Bcl-2 and Bcl-xL $[14,15]$. Activation of ERK inhibits caspase-8 cleavage and translocation of Bax and consequently suppresses the release of cytochrome $c$ from mitochondria [46]. TNF- $\alpha$-induced apoptosis in polyamine-depleted IEC-6 cells, a nontransformed intestinal crypt epithelial cell line, was prevented by ERK1/2 activation [47]. ERK1/2 activation is implicated in the facilitation of regeneration [44]. In the present study, PDRN treatment enhanced phosphorylation of ERK1/2 in the colonic tissues of ischemic colitis rats (Figure 5, right-lower), which might contribute to inhibiting apoptosis. The present results showed that the inhibitory effect of PDRN on apoptosis appeared through phosphorylation of ERK1/2.

\section{Conclusions}

PDRN treatment reduced the morphological score and colonic damage score. This promising therapeutic effect of
PDRN on colonic damage may be attributable to its ability to enhance $\mathrm{A}_{2 \mathrm{~A}} \mathrm{R}$ expression. PDRN also improved gastric ulcer healing by suppressing inflammatory cytokines, such as TNF- $\alpha$, IL- $1 \beta$, and IL- 6 through $A_{2 A}$ R. In addition, the present study additionally observed a relationship between DMPX, a specific adenosine $A_{2 A}$ receptor antagonist, and PDRN in a model of ischemic colitis. These findings strongly support that PDRN may be efficacious in the treatment. The present results suggest that PDRN possesses therapeutic efficacy for ischemic colitis by increasing VEGF expression and inhibiting inflammatory cytokines through enhancing $\mathrm{A}_{2 \mathrm{~A}} \mathrm{R}$ expression.

\section{Data Availability}

All data generated or analyzed during the present study are included in this article.

\section{Conflicts of Interest}

The authors declare no conflicts of interest.

\section{Authors' Contributions}

Sung-Eun Kim and Il-Gyu Ko contributed equally to this work. J. W. Jeon conceived and designed the experiments. J. J. Jin, E. S. Ji, L. Hwang, S. H. Kim, and J. H. Han performed the experiments. C. J. Kim performed data analysis and interpretation. S. E. Kim and I. G. Ko wrote the manuscript.

\section{Acknowledgments}

This study was supported by a grant from the National Research Foundation of Korea (NRF-2015R1C1A1A02036985).

\section{References}

[1] M. Doulberis, P. Panagopoulos, S. Scherz, E. Dellaporta, and G. Kouklakis, "Update on ischemic colitis: from etiopathology to treatment including patients of intensive care unit," Scandinavian Journal of Gastroenterology, vol. 51, no. 8, pp. 893-902, 2016.

[2] J. R. Scharff, W. E. Longo, S. M. Vartanian, D. L. Jacobs, A. N. Bahadursingh, and D. L. Kaminski, "Ischemic colitis: spectrum of disease and outcome," Surgery, vol. 134, no. 4, pp. 624-629, 2003.

[3] P. D. R. Higgins, K. J. Davis, and L. Laine, "The epidemiology of ischaemic colitis," Alimentary Pharmacology and Therapeutics, vol. 19, no. 7, pp. 729-738, 2004.

[4] T. Kimura, A. Shinji, A. Horiuchi et al., "Clinical characteristics of young-onset ischemic colitis," Digestive Diseases and Sciences, vol. 57, no. 6, pp. 1652-1659, 2012.

[5] A. Theodoropoulou and I. E. Koutroubakis, "Ischemic colitis: clinical practice in diagnosis and treatment," World Journal of Gastroenterology, vol. 14, no. 48, pp. 7302-7308, 2008.

[6] C. Washington and J. C. Carmichael, "Management of ischemic colitis," Clinics in Colon and Rectal Surgery, vol. 25, no. 4, pp. 228-235, 2012.

[7] K. Lammers, G. Innocenti, A. Venturi et al., "The effect of transient intestinal ischemia on inflammatory parameters," International Journal of Colorectal Disease, vol. 18, no. 1, pp. 78-85, 2003. 
[8] O. Karatepe, A. Cakir, O. Unal et al., "Iloprost reduces colonic injury in ischemic colitis in rats," Acta Cirurgica Brasileira, vol. 26, no. 3, pp. 220-226, 2011.

[9] G. E. Caughey, L. G. Cleland, P. S. Penglis, J. R. Gamble, and M. J. James, "Roles of cyclooxygenase (COX)-1 and COX-2 in prostanoid production by human endothelial cells: selective up-regulation of prostacyclin synthesis by COX-2," The Journal of Immunology, vol. 167, no. 5, pp. 2831-2838, 2001.

[10] B. Lugo, H. R. Ford, and A. Grishin, "Molecular signaling in necrotizing enterocolitis: regulation of intestinal COX-2 expression," Journal of Pediatric Surgery, vol. 42, no. 7, pp. 1165-1171, 2007.

[11] Z. Sandor, X. M. Deng, T. Khomenko, A. S. Tarnawski, and S. Szabo, "Altered angiogenic balance in ulcerative colitis: a key to impaired healing?" Biochemical and Biophysical Research Communications, vol. 350, no. 1, pp. 147-150, 2006.

[12] J. W. Jeon, J. I. Lee, H. P. Shin et al., “Adenosine A2A-receptor agonist polydeoxyribonucleotide promotes gastric ulcer healing in Mongolian gerbils," Animal Cells and Systems, vol. 18, no. 6, pp. 399-406, 2014.

[13] R. Dirisina, R. B. Katzman, T. Goretsky et al., "p53 and PUMA independently regulate apoptosis of intestinal epithelial cells in patients and mice with colitis," Gastroenterology, vol. 141, no. 3, pp. 1036-1045, 2011.

[14] X. Deng, P. Ruvolo, B. Carr, and W. S. May Jr., "Survival function of ERK1/2 as IL-3-activated, staurosporine-resistant Bcl2 kinases," Proceedings of the National Academy of Sciences, vol. 97, no. 4, pp. 1578-1583, 2000.

[15] M. May, M. Uchida, T. Watanabe et al., "Activation of extracellular signal-regulated kinases ERK1 and ERK2 induces Bcl-xL up-regulation via inhibition of caspase activities in erythropoietin signaling," Journal of Cellular Physiology, vol. 195, no. 2, pp. 290-297, 2003.

[16] J. B. Seidelin and O. H. Nielsen, "Attenuated apoptosis response to Fas-ligand in active ulcerative colitis," Inflammatory Bowel Diseases, vol. 14, no. 12, pp. 1623-1629, 2008.

[17] F. Veronesi, D. Dallari, G. Sabbioni, C. Carubbi, L. Martini, and M. Fini, "Polydeoxyribonucleotides (PDRNs) from skin to musculoskeletal tissue regeneration via adenosine A2A receptor involvement," Journal of Cellular Physiology, vol. 232, no. 9, pp. 2299-2307, 2017.

[18] D. Altavilla, A. Bitto, F. Polito et al., "Polydeoxyribonucleotide (PDRN): a safe approach to induce therapeutic angiogenesis in peripheral artery occlusive disease and in diabetic foot ulcers," Cardiovascular \& Hematological Agents in Medicinal Chemistry, vol. 7, no. 4, pp. 313-321, 2009.

[19] O. Irkorucu, O. Taşcilar, G. K. Çakmak et al., "The effect of sildenafil on an animal model for ischemic colitis," Digestive Diseases and Sciences, vol. 53, no. 6, pp. 1618-1623, 2008.

[20] L. J. Brandt and P. Feuerstadt, "Beyond low flow: how I manage ischemic colitis," American Journal of Gastroenterology, vol. 111, no. 12, pp. 1672-1674, 2016.

[21] J. L. Wallace and C. M. Keenan, “An orally active inhibitor of leukotriene synthesis accelerates healing in a rat model of colitis," The American Journal of Physiology, vol. 258, no. 4, pp. 527-534, 1990.

[22] S. Korehisa, T. Ikeda, S. Okano et al., "A novel histological examination with dynamic three-dimensional reconstruction from multiple immunohistochemically stained sections of a PD-L1-positive colon cancer," Histopathology, vol. 72, no. 4, pp. 697-703, 2018.

[23] M. Y. Zhu, Y. M. Lu, Y. X. Ou, H. Z. Zhang, and W. X. Chen, "Dynamic progress of 2,4,6-trinitrobenzene sulfonic acid induced chronic colitis and fibrosis in rat model," Journal of Digestive Diseases, vol. 13, no. 8, pp. 421-429, 2012.

[24] I.-G. Ko, S.-E. Kim, J.-J. Jin et al., "Combination therapy with polydeoxyribonucleotide and proton pump inhibitor enhances therapeutic effectiveness for gastric ulcer in rats," Life Sciences, vol. 203, pp. 12-19, 2018.

[25] H. Jin, J. Guo, J. Liu et al., "Anti-inflammatory effects and mechanisms of vagal nerve stimulation combined with electroacupuncture in a rodent model of TNBS-induced colitis," American Journal of Physiology-Gastrointestinal and Liver Physiology, vol. 313, no. 3, pp. G192-G202, 2017.

[26] G. Pallio, A. Bitto, G. Pizzino et al., "Adenosine receptor stimulation by polydeoxyribonucleotide improves tissue repair and symptomology in experimental colitis," Frontiers in Pharmacology, vol. 7, p. 273, 2016.

[27] U. Billmeier, W. Dieterich, M. F. Neurath, and R. Atreya, "Molecular mechanism of action of anti-tumor necrosis factor antibodies in inflammatory bowel diseases," World Journal of Gastroenterology, vol. 22, no. 42, pp. 9300-9313, 2016.

[28] M. H. Holtmann, M. Schütz, P. R. Galle, and M. F. Neurath, "Functional relevance of soluble TNF- $\alpha$, transmembrane TNF- $\alpha$ and TNF-signal transduction in gastrointestinal diseases with special reference to inflammatory bowel diseases," Zeitschrift für Gastroenterologie, vol. 40, no. 8, pp. 587-600, 2002.

[29] R. Atreya and M. F. Neurath, "Involvement of IL-6 in the pathogenesis of inflammatory bowel disease and colon cancer," Clinical Reviews in Allergy \& Immunology, vol. 28, no. 3, pp. 187-196, 2005.

[30] S. Yamamoto, M. Tanabe, G. Wakabayashi, M. Shimazu, K. Matsumoto, and M. Kitajima, "The role of tumor necrosis factor- $\alpha$ and interleukin- $1 \beta$ in ischemia-reperfusion injury of the rat small intestine," Journal of Surgical Research, vol. 99, no. 1, pp. 134-141, 2001.

[31] L. J. Crofford, P. E. Lipsky, P. Brooks, S. B. Abramson, L. S. Simon, and L. B. A. van de Putte, "Basic biology and clinical application of specific cyclooxygenase-2 inhibitors," Arthritis \& Rheumatism, vol. 43, no. 1, pp. 4-13, 2000.

[32] L. M. Kreckler, T. C. Wan, Z.-D. Ge, and J. A. Auchampach, "Adenosine inhibits tumor necrosis factor- $\alpha$ release from mouse peritoneal macrophages via $\mathrm{A}_{2 \mathrm{~A}}$ and $\mathrm{A}_{2 \mathrm{~B}}$ but not the $\mathrm{A}_{3}$ adenosine receptor," Journal of Pharmacology and Experimental Therapeutics, vol. 317, no. 1, pp. 172-180, 2006.

[33] F. Squadrito, A. Bitto, N. Irrera et al., "Pharmacological activity and clinical use of PDRN," Frontiers in Pharmacology, vol. 8, p. 224, 2017.

[34] L. Antonioli, M. Fornai, R. Colucci et al., "The blockade of adenosine deaminase ameliorates chronic experimental colitis through the recruitment of adenosine $\mathrm{A}_{2 \mathrm{~A}}$ and $\mathrm{A}_{3}$ receptors," Journal of Pharmacology and Experimental Therapeutics, vol. 335, no. 2, pp. 434-442, 2010.

[35] K. P. Lund and R. J. Rigby, "What are the mechanisms of fibrosis in IBD?" Inflammatory Bowel Diseases, vol. 14, pp. S127-S128, 2008.

[36] A. L. Theiss, J. G. Simmons, C. Jobin, and P. K. Lund, "Tumor necrosis factor (TNF) $\alpha$ increases collagen accumulation and proliferation in intestinal myofibroblasts via TNF receptor 2," Journal of Biological Chemistry, vol. 280, no. 43, pp. 3609936109, 2005.

[37] J. Meregnani, D. Clarençon, M. Vivier et al., "Anti-inflammatory effect of vagus nerve stimulation in a rat model of inflammatory bowel disease," Autonomic Neuroscience: Basic \& Clinical, vol. 160, no. 1-2, pp. 82-89, 2011. 
[38] T. Okuda, T. Azuma, M. Ohtani et al., "Hypoxia-inducible factor 1 alpha and vascular endothelial growth factor overexpression in ischemic colitis," World Journal of Gastroenterology, vol. 11, no. 10, pp. 1535-1539, 2005.

[39] I. Ernens, F. Léonard, M. Vausort, M. Rolland-Turner, Y. Devaux, and D. R. Wagner, "Adenosine up-regulates vascular endothelial growth factor in human macrophages," Biochemical and Biophysical Research Communications, vol. 392, no. 3, pp. 351-356, 2010.

[40] A. Bitto, F. Polito, D. Altavilla, L. Minutoli, A. Migliorato, and F. Squadrito, "Polydeoxyribonucleotide (PDRN) restores blood flow in an experimental model of peripheral artery occlusive disease," Journal of Vascular Surgery, vol. 48, no. 5, pp. 1292-1300, 2008.

[41] F. Polito, A. Bitto, M. Galeano et al., "Polydeoxyribonucleotide restores blood flow in an experimental model of ischemic skin flaps," Journal of Vascular Surgery, vol. 55, no. 2, pp. 479-488, 2012.

[42] D. Y. Liu, R. Xu, M. F. Huang et al., "Si Shen Wan regulates phospholipase $\mathrm{C} \gamma-1$ and PI3K/Akt signal in colonic mucosa from rats with colitis," Evidence-Based Complementary and Alternative Medicine, vol. 2015, Article ID 392405, 7 pages, 2015.

[43] S.-S. Baek and S.-H. Kim, "Treadmill exercise ameliorates symptoms of Alzheimer disease through suppressing microglial activation-induced apoptosis in rats," Journal of Exercise Rehabilitation, vol. 12, no. 6, pp. 526-534, 2016.

[44] Y.-M. Kim, J.-J. Jin, S.-J. Lee, T.-B. Seo, and E.-S. Ji, “Treadmill exercise with bone marrow stromal cells transplantation facilitates neuroprotective effect through BDNF-ERK1/2 pathway in spinal cord injury rats," Journal of Exercise Rehabilitation, vol. 14, no. 3, pp. 335-340, 2018.

[45] A. Benchoua, C. Guégan, C. Couriaud et al., "Specific caspase pathways are activated in the two stages of cerebral infarction," The Journal of Neuroscience, vol. 21, no. 18, pp. 7127-7134, 2001.

[46] T. S. Söderström, M. Poukkula, T. H. Holmström, K. M. Heiskanen, and J. E. Eriksson, "Mitogen-activated protein kinase/extracellular signal-regulated kinase signaling in activated $\mathrm{T}$ cells abrogates TRAIL-induced apoptosis upstream of the mitochondrial amplification loop and caspase8," The Journal of Immunology, vol. 169, no. 6, pp. 2851-2860, 2002.

[47] S. Bhattacharya, R. M. Ray, and L. R. Johnson, "Prevention of TNF- $\alpha$-induced apoptosis in polyamine-depleted IEC- 6 cells is mediated through the activation of ERK1/2," American Journal of Physiology-Gastrointestinal and Liver Physiology, vol. 286, no. 3, pp. G479-G490, 2004. 